\title{
The Anticoagulant and Nonanticoagulant Properties of Heparin
}

\author{
Danielle M. H. Beurskens ${ }^{10}$ Joram P. Huckriede ${ }^{1}$ \\ Chris P. Reutelingsperger ${ }^{1}$ Gerry A. F. Nicolaes ${ }^{1}$ \\ ${ }^{1}$ Department of Biochemistry, Cardiovascular Research Institute \\ Maastricht, Maastricht University, Maastricht, The Netherlands \\ ${ }^{2}$ Synapse BV, Cardiovascular Research Institute Maastricht, \\ Maastricht University, Maastricht, The Netherlands
}

\author{
Roy Schrijver $^{1} \quad$ H. Coenraad Hemker ${ }^{2}$
}

\begin{abstract}
Address for correspondence Gerry A. F. Nicolaes, PhD, Department of Biochemistry, Cardiovascular Research Institute Maastricht, Maastricht University, Maastricht 6229 ER, The Netherlands (e-mail: g.nicolaes@maastrichtuniversity.nl).
\end{abstract}

Thromb Haemost 2020;120:1371-1383.

\begin{abstract}
Keywords

- heparin

- anticoagulation

- metastasis

- inflammation

Heparins represent one of the most frequently used pharmacotherapeutics. Discovered around 1926, routine clinical anticoagulant use of heparin was initiated only after the publication of several seminal papers in the early 1970s by the group of Kakkar. It was shown that heparin prevents venous thromboembolism and mortality from pulmonary embolism in patients after surgery. With the subsequent development of low-molecular-weight heparins and synthetic heparin derivatives, a family of related drugs was created that continues to prove its clinical value in thromboprophylaxis and in prevention of clotting in extracorporeal devices. Fundamental and applied research has revealed a complex pharmacodynamic profile of heparins that goes beyond its anticoagulant use. Recognition of the complex multifaceted beneficial effects of heparin underscores its therapeutic potential in various clinical situations. In this review we focus on the anticoagulant and nonanticoagulant activities of heparin and, where possible, discuss the underlying molecular mechanisms that explain the diversity of heparin's biological actions.
\end{abstract}

\section{Heparin Structure and Biosynthesis}

Heparin is a biomolecule that belongs to the class of glycosaminoglycans (GAGs). GAGs exist as large linear polysaccharide structures, composed of repeated structural motifs. Besides heparin, the family of GAGs includes heparan sulfate (HS), dermatan sulfate, chondroitin sulfate (CS), keratan sulfate, and hyaluronan. Each of these GAGs is composed of different repeating disaccharide units and, with the exception of hyaluronan, is sulfated at various positions. These sulfations introduce functionally important negatively charged groups to the GAGs. Both heparin and HS are complex heterogeneous mixtures of repeating uronic acid and D-glucosamine/N-acetyl-D-glucosamine units, with heparin being generally relatively smaller and containing relatively more sulfated groups than $\mathrm{HS}^{1}{ }^{1}$ The biological

received

February 12, 2020

accepted after revision

July 3, 2020 functions of heparin are for a large part dependent on electrostatic interactions and the influence of sulfation on these functions have been well described since decades. ${ }^{2}$

Heparin biosynthesis occurs in mammalian cells through a complex process that involves many enzymatic steps. After a core tetrasaccharide linker is synthesized, by sequential transfer of monosaccharide units onto a cell-type-specific core protein, serglycin proteoglycan in the case of heparin, heparin synthesis starts. The tetrasaccharide linker is attached to the side-chain oxygen atom of a serine residue and thereby forms an O-linked glycan. The linker then serves as the template onto which heparosan, the precursor molecule of heparin (and of $\mathrm{HS}$ ), is synthesized by sequential enzymatic transfer of defined disaccharide units. These saccharide units subsequently undergo further posttranslational processing, including sulfations, and will finally result in the mature polyanionic heparin (c) 2020 Georg Thieme Verlag KG Stuttgart · New York
DOI https://doi.org/ 10.1055/s-0040-1715460. ISSN 0340-6245. 
proteoglycan molecules that are found exclusively in mast cell granules. Here, the heparin proteoglycans serve to concentrate the various positively charged cytokines, growth factors, and proteases that become secreted upon mast cell stimulation/ degranulation. This unique localization is in contrast to the ubiquitously expressed HS proteoglycans (HSPGs), which exist as part of proteoglycans in the extracellular matrix (ECM). Through mild acidic hydrolysis or via random cleavage at glucuronic acid residues by endo- $\beta$-D-glucuronidase, a heterogeneous mixture of heparin molecules ranging from 5 to $25 \mathrm{kDa}$ in molar weight can be generated. Of the fully processed heparin molecules, only one in three is able to bind to antithrombin (AT). ${ }^{3}$ The pharmaceutical-grade heparin that is extracted from animal tissues (mostly porcine mucosa) and that contains the mixture of heparin molecules with varying molecular weights is called unfractionated heparin (UFH).

The ubiquitously expressed HSPGs are also heterogeneous with only less than $5 \%$ of endothelial HSPG able to bind AT. ${ }^{3}$ Despite this low percentage, the contribution of HSPGs to anticoagulant homeostasis in the vasculature is considered important due to their presence in the endothelial glycocalyx, thereby contributing to the overall nonthrombogenic nature of the vessel wall under physiological conditions.

The majority of heparins currently being used have been purified from porcine and bovine intestinal mucosa and to a lesser extent from bovine lungs that are collected in the slaughterhouse. These tissues are rich in mast cells that form a first-line defense against invading pathogens. Potential contamination of pharmaceutical heparin together with the vulnerability of the supply chain and increasing demand has led to the consideration of other animal sources and bioengineered heparin. ${ }^{4}$ However, none of these alternative strategies has yet led to a large-scale production of pharmaceutical-grade heparin.

\section{Heparin and Its Derivatives}

The discovery of the separability of heparins' anticoagulant effects toward coagulation factor Xa (FXa) and thrombin (see the next section on anticoagulant properties of heparin) led to the development of shorter heparin variants with optimized anticoagulant activity and reduced bleeding risk as compared with UFH. These heparins are obtained by fragmentation of UFH by chemical or enzymological means and are commonly described as low-molecular-weight heparins (LMWHs). While UFH molecules may range in size from 6 to $60 \mathrm{kDa}$, those for LMWHs vary between 1 and $10 \mathrm{kDa} .^{5,6}$ Many different types of LMWHs exist (e.g., Food and Drug Administration-approved dalteparin, enoxaparin, and tinzaparin) with the more recent generation of second-generation LMWH or ultralow molecular weight heparins such as bemiparin and semuloparin (reviewed in Walenga and Lyman ${ }^{7}$ ). All these LMWH preparations express different activities toward FXa and have different pharmacokinetic profiles. Consequently, they have different applications in clinical practice.

The use of LMWH offers several advantages over UFH as the former has a higher bioavailability, allows better predictable dosing, and is associated with less adverse reactions. As a result, LMWH has become the heparin of choice in many standard clinical situations such as venous thromboembolism (VTE), major surgery, and acute coronary syndrome. ${ }^{7,8}$ UFH, however, remains preferred in situations such as prevention of coagulation in extracorporeal devices and in patients with renal failure due to less dependence on the kidneys for clearance and improved reversibility with protamine. $^{9}$

Considering the drawbacks of heparin isolated from animal origin, a synthetic anticoagulant with a high affinity toward AT was developed. ${ }^{10}$ The compound in question, fondaparinux, comprises a specific "pentasaccharide sequence" and will be discussed in the next section in more detail (see Anticoagulant Properties of Heparin). Fondaparinux is approved for the prevention and therapy of VTE after major surgery, and has been successfully applied in patients with, e.g., myocardial infarction. ${ }^{11}$ Likewise selective modified forms of heparins such as (de)sulfated, deacetylated, or glycol-split heparins are being developed as alternative nonanticoagulant drugs and are currently being tested in preclinical and clinical studies for their application in particular settings. ${ }^{12}$

\section{Anticoagulant Properties of Heparin}

Of all its functions, the anticoagulant action of heparin has been described best. It is based on a proposed combined template-based/allosteric mechanism for the interaction between the plasma serine proteinase inhibitor AT and either thrombin or FXa. Although the inhibition of factors VIIa, IXa, XIa, and kallikrein by AT is also stimulated by heparin, these will not be discussed here as these are regarded of overall lesser importance than the inhibition of FXa and thrombin.

Heparin facilitates the interaction between AT and thrombin (or FXa) by binding tightly with a specific site to AT. This site is known as the "pentasaccharide sequence," consisting of a specific sequence of five highly sulfated sugar units in the heparin polymer. ${ }^{13,14}$ - Fig. 1A shows an experimentally derived structure for the ternary complex composed of a synthetic heparin mimetic binding both thrombin and AT. ${ }^{15}$

Moreover, AT undergoes a conformational change upon binding to heparin ( - Fig. 1B). This change makes AT about twice as reactive to thrombin and up to 100 times more reactive to FXa. ${ }^{16,17}$ The remaining 100 - to 1,000 -fold increase of activity is due to the fact that thrombin binds loosely and aspecifically to the remainder of the heparin chain and is then guided rapidly to the bound AT by onedimensional approximation along the heparin molecule. FXa inactivation is subject to the same mechanism but binds 10 times less strongly than thrombin and is inactivated three times less efficiently. ${ }^{18}$ The interaction between the complex of heparin and AT with FXa or thrombin is thus essentially different. FXa can interact with the pentasaccharide-AT complex as such, whereas inactivation of thrombin requires a "slide" of 17 sugar units at the nonreducing end of the pentasaccharide. ${ }^{19}$ Given this requirement in sugar length for the inactivation of thrombin by the heparin-AT complex, the "slide" can best occur with UFH and not with LMWH. ${ }^{9}$ 
A

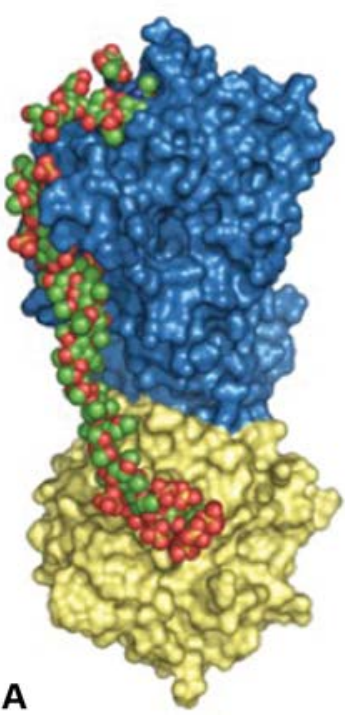

B

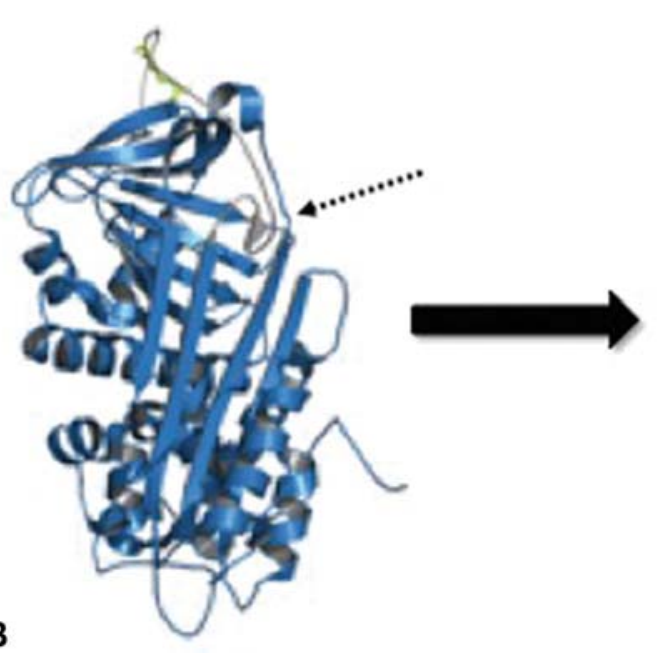

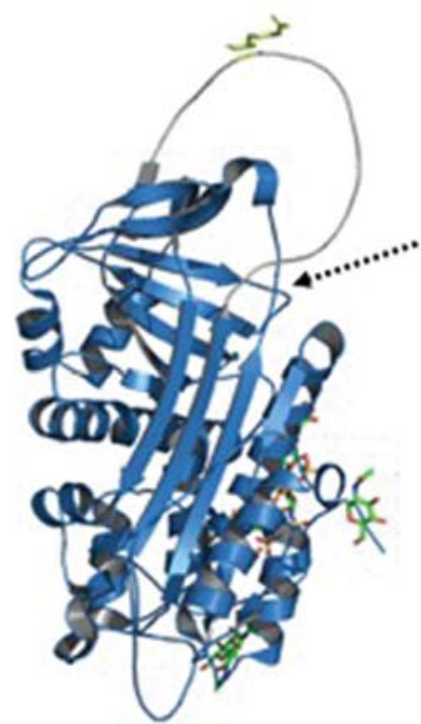

Fig. 1 The interaction of heparin with antithrombin (AT) and thrombin. Three-dimensional structure of the ternary complex between thrombin and AT, bound to the heparin mimetic, SR123781. (A) Shown are the surface structures of thrombin (pale yellow) and AT (blue) that are bound by a heparin fragment (as ball presentation in red and green). This structure represents the $2.5 \AA$ crystal structure as is deposited in the protein data bank by accession number 1TB6.pdb. ${ }^{15}$ (B) Conformational change in AT induced by the binding of the pentasaccharide. Left: crystal structure of monomeric AT (1F1T.pdb, in blue) in the nonbound state, with the reactive center loop in gray and P1 residue Arg393 in yellow. Note the hinge region (as indicated by the dashed arrow) in a folded conformation. Right: upon binding of a pentasaccharide (as indicated by the ring structures in green and red) the hinge region assumes a more elongated conformation, causing the reactive center loop (in gray) and the P1 residue (in yellow) to be exposed (from PDB coordination file 2GD4.pdb).

\section{Heparin as a Direct and Indirect Modifier of Coagulation Pathways}

The registration and application of heparin as an anticoagulant has spurred the research into mechanistic studies to explain the beneficial effects observed with its clinical use. Interestingly, not only antithrombotic functions were recorded but also a wide variety of nonanticoagulant properties of heparin were elucidated. These nonanticoagulant properties include heparin-mediated modulation of adhesion molecules, ${ }^{20,21}$ heparin-induced release of endothelial-bound tissue factor pathway inhibitor (TFPI), ${ }^{22}$ modulation of fibrinolytic activators such as tissue plasminogen activator, ${ }^{23}$ the binding of chemokines and cytokines, ${ }^{24}$ and more recently the neutralization of damage-associated molecular patterns (DAMPS). ${ }^{25}$

Hence, heparin expresses anticoagulant and nonanticoagulant activities ( - Fig. 2) that collectively contribute to the therapeutic effects observed in the wide range of clinical applications of heparin (-Table $\mathbf{1}$ ).

It should be mentioned that also procoagulant/antifibrinolytic properties of heparin have been observed. These include the stimulation of the inhibition of activated protein $\mathrm{C}$ by protein $C$ inhibitors, ${ }^{26}$ the attenuation of fibrinolytic pathways, ${ }^{27}$ the altered inactivation of coagulation factor $\mathrm{Va},{ }^{28}$ and the stimulation of clotting of FXa-initiated coagulation of plasma. ${ }^{3}$ The latter two properties, however, have been tested in the absence of AT. Such conditions may occur in individuals with a consumptive coagulopathy. Treating individuals with heparin may cause depletion of AT. ${ }^{29}$ Further, of interest here are (1) the observed acceleration of thrombin formation that occurs through inhibition of TFPI function by the nonanticoagulant proteoglycan AV513, ${ }^{30}$ an effect which promotes the activation of coagulation factor $\mathrm{V}^{3}$ and (2) the procoagulant properties of polyphosphate, a linear polyanionic polymer of inorganic phosphate, ${ }^{31}$ as well as of extracellular RNA, ${ }^{32}$ both of which induce autoactivation of coagulation factors XII and $\mathrm{XI}$, but cannot substitute for heparin as an anticoagulant.

\section{Nonanticoagulant Properties of Heparin}

Although heparin was discovered and developed as an anticoagulant, it was realized that roughly $70 \%$ of the heparin molecules in UFH did not bind to $\mathrm{AT}^{33-35}$ a fraction which was termed "inactive heparin" ${ }^{34}$ or "low-affinity material." ${ }^{33,35}$ Hence, over the years patients receiving UFH have been injected also with "inactive" heparin molecules. Given the low frequency and accepted minor side effects of UFH use, the "inactive" heparin molecules may have contributed positively to the overall therapeutic effects of UFH.

Indeed, it has been realized that the earlier termed "inactive" fraction of heparin contains activities that appear to be tissue-protective. In those clinical situations where use of heparin as an anticoagulant is indicated, tissue damage through ischemia and reperfusion is frequent. Therefore, in retrospect nonanticoagulant beneficial properties of heparin may well have contributed to the success of heparin.

Acknowledging the observed nonanticoagulant properties of heparin, both UFH and LMWH have been applied for several other applications besides their use as antithrombotic therapeutics. These include applications such as surface coating of biomedical devices, treatment of hemodynamic disorders, modulation of growth factors, and serving as an adjunct to chemotherapeutic and anti-inflammatory drugs. Currently there are nearly 250 different manually reviewed entries in 


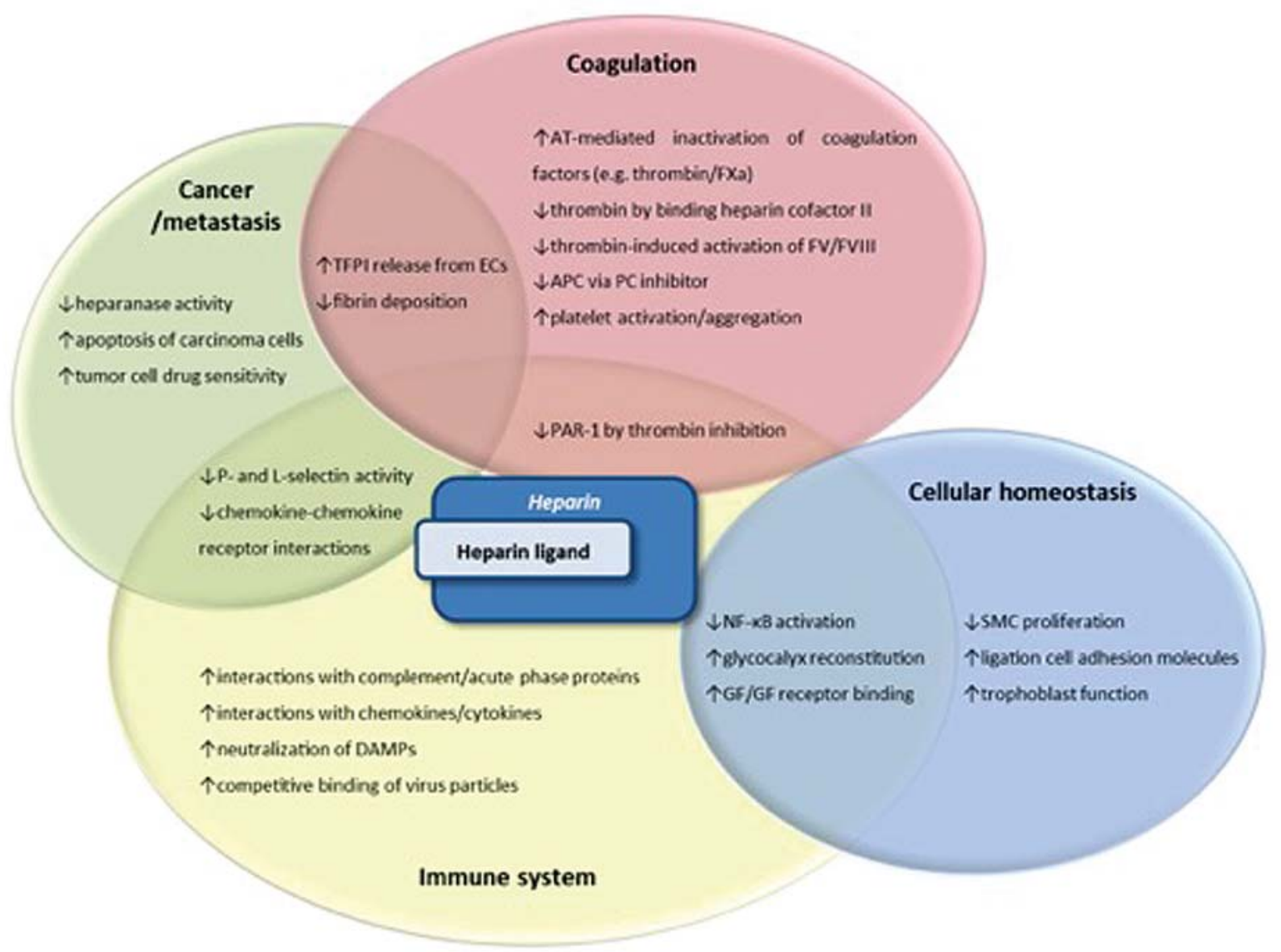

Fig. 2 Heparin-ligand interactions in physiological and pathological states. Schematic illustration of the polypharmacological properties of heparin in cancer/metastasis (green), coagulation (red), cellular homeostasis (blue), the immune system (yellow), or properties able to affect multiple of these processes. Binding of heparin to a plethora of heparin-binding biomolecules may result in alterations of important physiological processes and affect physiological states. (A)PC, (activated) protein C; AT, antithrombin; DAMPs, damage-associated molecular patterns; ECs, endothelial cells; GF, growth factor; PAR-1, protease activated receptor-1; SMC, smooth muscle cell; TFPI, tissue factor pathway inhibitor.

Table 1 Physiological/pathological states and medical procedures for which heparin is being applied

\begin{tabular}{|l|l|l|l|}
\hline Targets and applications of heparin \\
\hline Acute myocardial infarction & Deep vein thrombosis & Ischemic stroke & Surgery \\
\hline Alzheimer's disease & Drug delivery & Pregnancy & Extracorporeal circulation and hemodialysis \\
\hline Atrial fibrillation & Infectious disease & Pulmonary embolism & Transplantation \\
\hline
\end{tabular}

Note: Heparin is a multifunctional biomolecule which is used in many different types of medical applications and for various physiological and pathological states. Some examples of heparin's targets and applications, as extracted from references throughout this text, are given.

the Swiss-Prot database for proteins that bind heparin and whose biological properties can be modulated by heparin. Modulating effects of heparin not necessarily depend on its anticoagulant activity and an increasing number of described effects can be contributed to heparin's nonanticoagulant properties. The following sections provide an overview of the most studied nonanticoagulant properties of heparin, supported, if possible, by molecular mechanisms that explain the observed effects of heparin.

\section{Growth Factor Modification}

Binding of growth factors to heparins has already been described in the 1980s. In fact, the preparation of purified growth factors can proceed efficiently through the use of affinity chromatography using immobilized heparin.

Several observations may help to explain the effects that heparins have on growth factor function and availability. HSPG-bound fibroblast growth factor-2 (FGF-2) was shown to enter cells via nonclathrin-mediated lipid raft-dependent pathways, thus preventing the FGF-2 to be directed toward the lysosomes. ${ }^{36}$ Notably, heparin needs charged molecules to be able to translocate to the cell nucleus and compete with DNA for binding to growth factors. ${ }^{37}$ It is known that many growth factors (e.g., vascular endothelial growth factor [VEGF], FGF, and platelet-derived growth factor [PDGF]) bind to GAGs present on the cell surface and in the ECM 
where they are deposited in the basement membrane. ${ }^{38}$ As such, these growth factors are protected from proteolytic inactivation or physical denaturation. ${ }^{39}$ At the same time, they can reside in the endothelial GAG layer and serve as a pool of ready-to-use growth factors that can for instance respond to vascular damage. When the GAG chains are broken down by physiological or pathological stimuli, the bound growth factors are released and may bind (likely in complex with the released GAG) to their respective cellular receptors. ${ }^{40}$ Since heparin can interact directly with both growth factors and their respective receptors, it acts as a bridging or coreceptor molecule which can mediate the formation of high-affinity growth factor-receptor complexes. Addition of exogenous heparin may thus compete with the cell-bound GAGs for binding to the immobilized growth factor pool and stabilize these growth factor-receptor complexes. This stabilization by heparin can result in signaling events and has been observed for heparin sequences exceeding a tetramer polysaccharide length of appropriate composition and structure. ${ }^{41,42}$ Interestingly, for the promotion of VEGF activity, soluble heparin with a chain length of $>22$ saccharides is required, while a chain length of $<18$ sugar units results in the inhibition of VEGF binding to its receptor. ${ }^{43}$ Therefore, LMWH appears to be a potent inhibitor of both angiogenesis and fibrosis. ${ }^{43,44}$

In recent years, novel applications of heparin-growth factor modifications have been investigated in the field of nano- and regenerative medicine. ${ }^{45}$ Heparin-tailored biomaterials/scaffolds, such as hydrogels, nanoparticles, polymers, and liposomes, have been studied in tissue engineering and drug-delivery applications. ${ }^{46}$ Using high-affinity delivery systems, heparin, growth factors, and/or drugs can site-specifically be delivered to the tissue of interest and exert effects depending on the delivery system.

\section{Antimetastatic Properties of Heparin}

Use of heparin as a potential chemotherapeutic adjunct has been under investigation for many years.

Interest in the antimetastatic properties of heparin was sparked by several clinical observations indicating that cancer patients who were treated with heparin or heparin derivatives for cancer-associated thromboembolic disease appeared to have prolonged survival. ${ }^{47,48}$ Several preclinical studies investigating predominantly melanoma or mammary carcinoma tumors aimed to elaborate on the anticancer and antimetastatic properties of heparin (reviewed in Borsig ${ }^{49}$ ).

Besides heparin's anti-FXa and antithrombin effects, an additional anticoagulant mechanism was suggested to be involved in metastatic mechanisms, namely the induction of TFPI release from cells, ${ }^{22,50}$ a phenomenon that is observed in cancer patients receiving heparin. ${ }^{51}$ TFPI exhibits antiangiogenic and antimetastatic effects in vitro and in vivo and its release is induced by both anticoagulant and nonanticoagulant LMWHs. ${ }^{52}$ Furthermore, heparin is thought to downregulate the expression and activity of tissue factor through modulation of growth factor receptor-mediated activation of nuclear factor-kappa B (NF-KB) ${ }^{53}$ Another potential antimetastatic mechanism of heparin is hypothesized to be the inhibition of fibrin deposition around tumor cells, which lifts the protection from cancer cells against immune cell attack. ${ }^{54}$

Besides these anticoagulant mechanisms through which heparin is able to exert anticancer properties, nonanticoagulant mechanisms are assumed to be involved in these effects as well. One of the contributing nonanticoagulant activities was proposed to be the modulation of selectin activity (see the Anti-inflammatory Properties section). Heparin is known to block P- and L-selectin binding to natural and tumor cell ligands. This implies that heparin is able to modify selectinmediated events, thereby influencing cell-cell interactions that drive tissue growth and differentiation. Interestingly, there appears to be specificity in the effects that glycans have on selectin binding, with, e.g., heparin and HS showing differential interaction with selectins. ${ }^{55}$ UFH and LMWH were shown to inhibit metastasis of carcinoma cells to an extent comparable to that of P-selectin deficient cells. ${ }^{49,56}$ It is however difficult to describe this selectin-blocking heparin property as being specifically antimetastatic since the exact mechanisms still remain under investigation. ${ }^{57,58}$

Modulation of chemokine-chemokine receptor interactions constitutes another action of heparin affecting cell migration and metastasis, as was shown for the chemokine receptor CXCR4 and its ligand CXCL12 through in vitro studies. ${ }^{59}$ Also the interaction of the integrin VLA-4 with its ligand VCAM- 1 was found to be inhibited by heparin, reducing melanoma cell adhesion and experimental melanoma metastasis. ${ }^{60}$ CXCR1/2 and CXCL8 are other potential targets for heparin. ${ }^{61}$ Heparanase is an endoglycosidase that degrades HS in the ECM and on cell surfaces. Inhibition of heparanase activity by heparin was shown to inhibit tumor invasion and metastasis. ${ }^{62}$ The inhibition is abolished by using a totally desulphated type of heparin. ${ }^{63}$

Other ways through which heparin is thought to exert anticancer effects are the direct induction of apoptosis of carcinoma cells through cell-cycle arrest ${ }^{64}$ and the enhancement of tumor cell sensitivity to chemotherapy by increasing drug uptake and reversing the downregulation of tumor suppressor genes. ${ }^{65,66}$ The Wnt signaling pathway is thought to be involved in this latter process. ${ }^{66}$ Recently it was also shown that galectin-3, a $\beta$-galactoside-binding protein which is commonly overexpressed in most types of cancers, can be inhibited by heparins, independent of their anticoagulant properties. The exact mechanism via which this inhibition results in reduced metastasis is unclear but ligation by heparin has clearly inhibitory effects on galectin-3-mediated cancer cell behavior. ${ }^{67}$

In view of the close interplay between the hemostatic system and those mechanisms that underlie processes of cancer cell growth and metastasis, it is likely that the observed therapeutic effects of heparin in cancer patients can be attributed to multiple effects of the drug. It appears that prescription of heparin (mainly LMWH or UFH) in cancer patients without associated thrombosis results in increased survival, in the absence of an increased bleeding risk, as was recently shown by means of a meta-analysis for particularly small cell lung cancer patients ${ }^{68}$ or in a randomized phase III study in nonsmall cell lung cancer patients. ${ }^{69}$ It should be noted, however, 
that a recent multicenter randomized trial evaluating the prophylactic use of $\mathrm{LMWH}$ in $>2,000$ lung cancer patients found no difference in overall or metastasis-free survival between heparin-treated and untreated groups, while there was an increase in clinically relevant nonmajor bleeding events. ${ }^{70,71}$ Other trials indicated that patients with a "better prognosis" might benefit most from heparin treatment. ${ }^{72-74}$

Of note, the aforementioned studies have used registered anticoagulant heparin formulations and it has been observed before that the antimetastatic properties do not depend on the anticoagulant functions of heparin. ${ }^{75,76}$ Potentially contributing to this is the activity of heparin cofactor II, a plasma serpin with anticoagulant activities, which is known to act through both pentasaccharide-containing heparin (anticoagulant heparin) as well as through nonanticoagulant heparin. Via both in vitro study and animal studies it was shown that heparin cofactor II enhances metastasis in nonsmall cell lung cancer, which supported an observed correlation between high pretreatment plasma levels of heparin cofactor II and a reduced survival. ${ }^{77}$ As such, nonanticoagulant heparins are being probed for their usefulness as adjuncts in preclinical antimetastatic models. Several studies suggest that such heparin derivatives could indeed provide the sought after anticancer effects, without affecting the coagulation system. ${ }^{76,78}$ The fact that these heparin forms can be dosed to higher concentrations without risking bleeding in patients may prove beneficial to their potential application.

Also, the effects of heparin on the inhibition of metastasis were not observed for fondaparinux, ${ }^{56}$ suggesting that the earlier listed anticoagulant properties are not per se the most significant contribution to the overall activity. Likewise, the mentioned inhibitory interaction of heparins with selectins is independent of the anticoagulant function of heparin and was described also for chemically modified forms of heparin in vitro. ${ }^{79}$ As the hemostatic system is involved in cancer development, it remains to be proven what the true therapeutic value of inclusion of nonanticoagulant heparin in cancer treatment is and what the best treatment strategy is in current clinical practice. Hence, the possibility that different types of heparin have different therapeutic effects in various types of cancer should be considered. Therefore, clinical studies are needed that are designed to determine anticancer effects of a specified heparin type in a specified patient population.

\section{Anti-inflammatory Properties of Heparin}

Given the fact that endogenously produced heparin is stored in the granules of mast cells, it may not be surprising that pharmaceutical-grade heparin has immunomodulatory properties. Mast cells play a major role in inflammatory and allergic diseases as they contribute to increased vascular permeability and to allergic and anaphylactic reactions. It has been reported that heparin from mast cells, which is structurally different from clinical-grade heparin, has proinflammatory properties via the stimulation of bradykinin, ${ }^{80}$ similar to what has been reported for oversulphated $\mathrm{CS}^{81}$ However, endogenous heparin-like GAGs present on the endothelial cell surface and administered heparin appear to have quite the opposite effect. Patients with pathologies having a distinct immunological component seem to benefit from administration of heparin because of its anti-inflammatory properties, even though the evidence is not always equally convincing. These pathologies include conditions such as asthma, allergic rhinitis, inflammatory bowel disease, ocular disorders, cystic fibrosis, and burns. ${ }^{82-86}$ Also in several cardiovascular conditions with a clear inflammatory component such as acute coronary syndrome, cardiopulmonary bypass, and thrombophlebitis, ${ }^{87-89}$ the use of heparin is beneficial. In organ preservation and transplantation, in which processes of both ischemia and reperfusion are apparent, heparin is used to reduce vascular thrombosis and ischemia-reperfusion injury. ${ }^{90,91}$ However, the exact benefit or risk of heparin treatment during different stages of these processes is still a subject of debate.

The mechanisms by which heparin and its derivatives are able to express their anti-inflammatory properties reflect their multifaceted effects in biological processes. The anti-inflammatory properties can be roughly divided into two modes of action (-Fig. 3): (1) modulation through binding to soluble plasma ligands and (2) modulation through binding to cellsurface-bound receptors or macromolecules, with potential effects on downstream signaling pathways. In this way, heparin is able to interfere with several (if not all) stages of leukocyte transmigration and extravasation into the target tissue.

\section{Modulation by Heparin through Binding of Soluble Plasma Ligands}

Heparin is known to interact with a wide variety of ligands, in particular proteins, and these interactions confer upon heparin its anti-inflammatory functions. Through binding of inflammatory mediators and enzymes, heparin can inhibit activation of inflammatory cells and subsequent propagation of the inflammatory response and tissue damage. ${ }^{92}$ Examples of such ligands are complement proteins which have been described to express changed functional properties upon heparin binding. ${ }^{93}$ Heparin interferes with both the classical and alternative complement pathways by binding and inhibiting the formation of several complement factors (e.g., active $\mathrm{C} 1$ complex, C3 convertase) as well as the membrane attack complex, interfering with terminal cell lysis. ${ }^{94}$

Likewise, proinflammatory molecules like chemokines and cytokines are able to bind to heparin, in which electrostatic forces and interaction sites seem to determine the relative affinity toward a particular molecule. ${ }^{95,96}$ Binding of cytokines to cell-surface GAGs and binding to mast-cell-derived heparins at the site of inflammation result in the concentration and protection of cytokines against proteolytic inactivation and rapid clearance from the circulation. Given that these cytokines and chemokines exert their proinflammatory functions through receptor-mediated events, the administration of exogenous heparin will result in competitive binding between the inflammatory mediators and either the endogenous GAGs/heparins or the administered heparin. Consequently, administered heparin can dissociate cytokines and other proteins from their stationary binding, as it is observed during an acute-phase reaction, in which heparin-binding proteins are elevated in post-heparin plasma. ${ }^{97}$ 


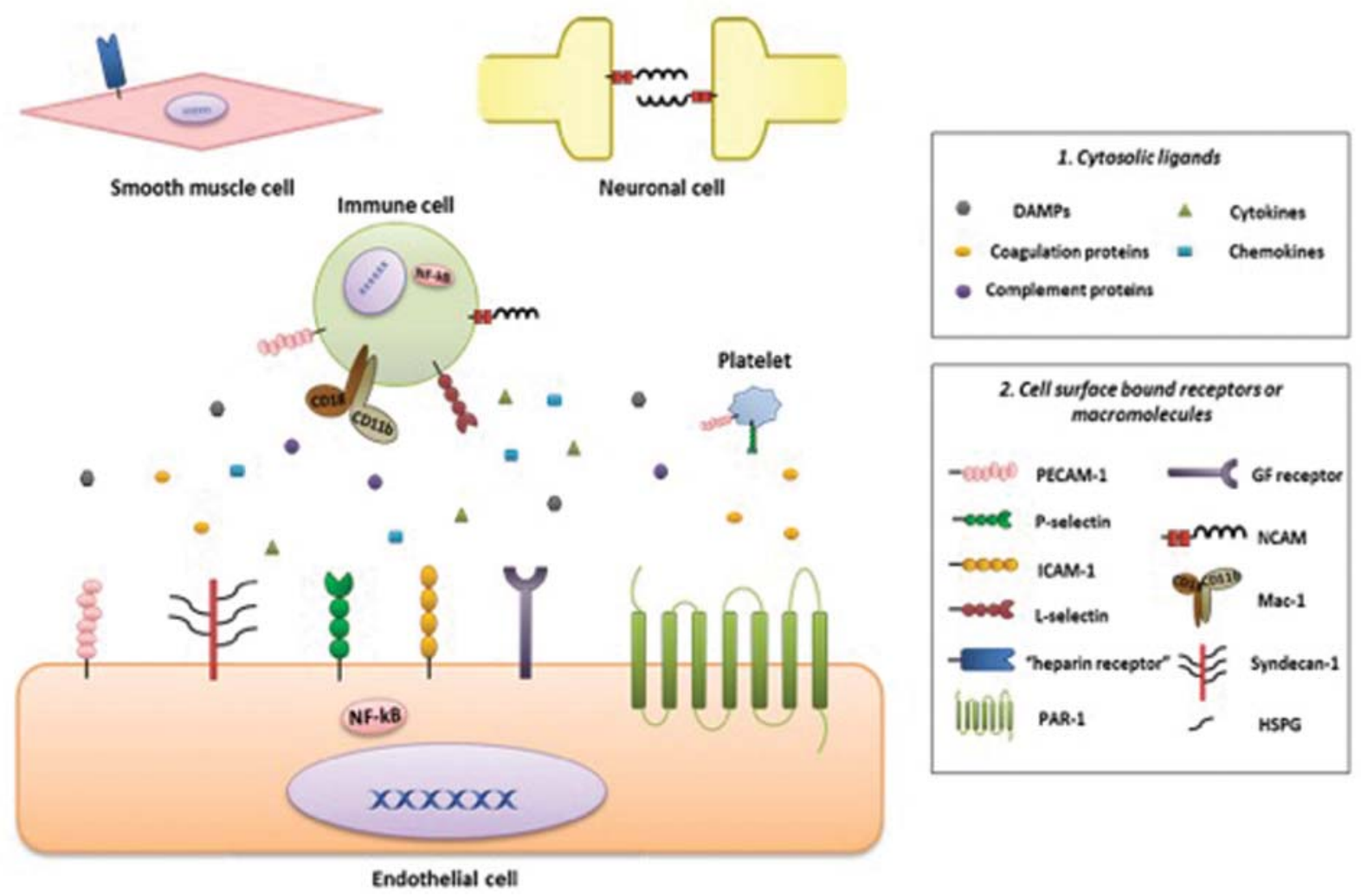

Fig. 3 The anti-inflammatory nature of heparin-ligand interactions. Illustration of the anti-inflammatory polypharmacology of heparin. Besides its use as an anticoagulant, the anti-inflammatory properties of heparin are widely recognized. These properties depend on the overall effect of heparin affecting many different ligands. These ligands can be either found in plasma, are surface-bound, or are present in the intracellular compartment.

In 2004 it was shown that nuclear proteins, although not present in the circulation under normal physiological conditions, may appear in plasma as a result of NETosis. ${ }^{98}$ NETosis is the process in which decondensed chromatins composed of nuclear DNA-histone scaffolds, designated neutrophil extracellular traps (NETs), are formed in response to a trigger, which is commonly a pathogen. Besides the DNA-histone network, NETs contain several granule proteins, oxidases, and elastases. ${ }^{98}$ Histones are known to be cytotoxic when present extracellularly. ${ }^{99}$ In vitro and in vivo experiments by Wildhagen and coworkers have shown that heparin is able to neutralize the cytotoxicity of extracellular histones through a mechanism that is independent of its anticoagulant properties, ${ }^{25}$ findings that were later confirmed. ${ }^{100,101}$ Furthermore, both heparin and HS were able to prevent accumulation of histones in the lungs of rabbits when administered prior to histone injection. ${ }^{102}$ Other granular proteins from activated immune cells such as elastase and cathepsin $\mathrm{G}$ have also been shown to be inhibited by heparin. ${ }^{103}$ NETs are a major component of arterial and venous thrombi, as demonstrated by several in vivo models and in patients, whereby LMWH was shown to prevent NETosis and thereby the extent of deep vein thrombosis in mice. ${ }^{104}$ This effect could demonstrate the strongest anticoagulant function of heparin.

It is worthwhile noting that heparin accelerates inhibition of thrombin by AT and, thereby, will affect also downstream thrombin targets/substrates, such as the protease activated receptor-1 (PAR-1). ${ }^{105}$ PAR receptors contribute to the proinflammatory response. Consequently, heparin dampens inflammation auxiliary to activated coagulation. An illustration of this intertwining of mechanisms is seen in the fact that in vivo thrombin formation can lead to inflammation, but also vice versa, in which a proinflammatory state may lead to thromboembolic events. ${ }^{106}$ In as much atherosclerosis can be seen as an inflammatory condition, it has been known for several decades that heparin use is associated with a lowered risk for atherosclerosis. Support for this association is given by the interplay between hemostatic and atherogenic processes, ${ }^{107}$ both of which are directly affected by the anticoagulant properties of heparin but also through the binding of heparin to other plasma and vessel-wall components (see also next paragraph). Collectively these effects result in a state in which the endothelial barrier function is preserved and thrombin generation and platelet adhesion are inhibited. Likewise, studies from the 1960s already showed that lipoprotein lipase activity in the blood is increased in the presence of heparin, resulting in reduced lipoprotein uptake by the vessel wall and an overall improved lipid profile by a lowering of low-density lipoproteins. ${ }^{108}$

\section{Heparin-Dependent Modulation of Cell-Surface-Bound Receptors or Macromolecules}

Several studies have shown that heparin is able to modify interactions between cells. Heparin-dependent binding to cell adhesion molecules as well as heparin-independent altered 
expression of adhesion molecules appears to mediate these effects. $^{55,109}$ Particularly, the inhibition of interactions between endothelial cells and blood cells (e.g., leukocytes, platelets) by heparin results in a more anti-inflammatory state, whereby heparin reduces tumor necrosis factor- $\alpha$ induced leukocyte rolling in vivo. ${ }^{110}$ This effect is likely caused by the binding of heparin to P-selectin that is present on the surface of activated endothelial cells and activated platelets. ${ }^{111}$ Heparin also binds L-selectin on the surface of leukocytes and has anti-inflammatory activity in vivo. ${ }^{112} \mathrm{HS}$ that is present on activated endothelial cells is known to be of importance for the adherence and rolling of leucocytes to the endothelium, and exogenously added heparins can interfere with and prevent this interaction. ${ }^{113,114}$ Interestingly, despite its structural similarity to P- and L-selectin, E-selectin does not bind heparin. ${ }^{55}$ This difference relies on two specific amino acid residues in the EGF-like domain, meaning that E-selectin would be able to bind heparin if these are altered. ${ }^{115}$ The reported downregulation of E-selectin and other adhesion molecules in heparin-treated endothelial cells is thought to occur (in part) through NF-kB inhibition. ${ }^{116}$ Intercellular adhesion molecule1 (ICAM-1), a cell adhesion molecule of the immunoglobulin superfamily of proteins which binds strongly to the integrins CD11a/CD18 or CD11b/CD18, is present in the membranes of both activated endothelial cells and leukocytes. ICAM-1 interactions are important for the maintenance of the barrier function of endothelial tissue and for leukocyte endothelial transmigration. Heparin was shown to attenuate ICAM-1mediated interactions by binding to this adhesion molecule ${ }^{117}$ and to suppress increased ICAM-1 expression during endothelial cell activation by reducing gene expression. ${ }^{118}$ Platelet endothelial cell adhesion molecule or PECAM-1, expressed on the surface of platelets and immune cells, which is involved in transmigration of immune cells, is thought to bind to heparin under preferable mild acidosis conditions. ${ }^{119,120}$ Also neuronal cell adhesion molecule (NCAM) ${ }^{121}$ and the integrin macrophage-1 antigen (Mac-1) ${ }^{122}$ have been shown to bind heparin. Mac- 1 is present on the surface of several immune cells, including neutrophils, macrophages, and natural killer cells. This pattern recognition receptor consists of protein subunits CD11b/CD18 and binds to several ligands including the complement proteins $\mathrm{iC} 3 \mathrm{~b}$ and $\mathrm{C} 4 \mathrm{~b}$ and several bacterial surface epitopes. Heparin binding to Mac-1 was shown to inhibit the binding of Mac- 1 ligands, resulting in modulation of inflammation and cell proliferation.

Heparin was also shown to influence interaction of viruses with cells and heparin can compete with cell-surface-bound HS for binding to several types of viruses. This attenuates the functional interaction between the virus and its target cells and thus can result in inhibition of infection. ${ }^{123-125}$

The above-mentioned receptor-mediated anti-inflammatory effects of heparin can be considered as in direct contrast to the effects resulting from the heparin-mediated inhibition of thrombin and FXa. Through the enhancement of inhibition of thrombin/FXa activity in vivo, heparin thus has a twofold indirect anti-inflammatory property since it is known to dampen the procoagulant responses of endothelial cells and platelets by limiting their activation by coagulation factors.
In addition it was shown that both heparin and low anticoagulant heparin act in a PAR-1-dependent manner through a mechanism that does not depend on thrombin binding and can thus directly interfere with cell signaling. ${ }^{126}$ The dampening effect of heparin on platelet reactivity appears in contrast to effects recorded for use of dabigatran, an oral anticoagulant (direct oral anticoagulant [DOAC]) for which it was shown that its use in a cohort of atrial fibrillation resulted in enhanced platelet reactivity and increased platelet PAR-1/PAR4 expression. ${ }^{127}$

In addition to endothelial cells, heparin also targets vascular smooth muscle cells (VSMCs) and modulates their biology. Heparin induces switching from VSMC synthetic to contractile phenotype and inhibits VSMC proliferation by interfering with cell-cycle progression. ${ }^{128}$ This property of heparin can be employed in stent technology to prepare coatings that control neointimal cell growth. ${ }^{129}$ The modulation of VSMCs appears to depend neither on the anionic charge $^{130}$ nor on the anticoagulant properties of heparin. ${ }^{131}$

Many experimental and clinical studies have illustrated in a more integrative approach the overall beneficial in vivo effects of heparin in inflammation. More recent studies confirmed that both UFH and LMWH reduce neutrophil sequestration and lung permeability with concomitant tissue protection in a rat model of lipopolysaccharide (LPS)-induced acute lung injury. ${ }^{132,133}$ The protective effect was likely independent of heparin's anticoagulant properties since heparins devoid of anticoagulant activity reduce neutrophil infiltration and protect lungs in a mouse model of LPS-induced sepsis. ${ }^{25}$

Finally, heparin acts positively on vascular endothelium by restoring glycocalyx function after inflammation-induced glycocalyx shedding. ${ }^{134,135}$ It is hypothesized that heparin can replenish the cell-surface proteoglycan network by mobilizing an intercellular pool of syndecan- $1^{136}$ and that heparin can take over partly the functions of syndecan- $1 .{ }^{137}$

As discussed above heparin can influence heparin-independent intracellular signaling through modulation of receptorligand interactions. Heparin was shown to inhibit p38 MAPK and NF-KB activation in an in vitro LPS-induced inflammatory response on endothelial cells ${ }^{138}$ as well as in an in vivo experimental model of LPS-induced inflammation. ${ }^{132}$ Likewise, heparin was able to alleviate endothelial barrier dysfunction through regulation of p38 MAPK in an inflammatory model induced by the DAMP high mobility group box 1 (HMGB1). ${ }^{139}$ While some report heparin does not affect the translocation of NF-kB into the nucleus, ${ }^{140}$ other have proposed that it may compete with DNA for NF-KB binding sites. ${ }^{138,141}$

Another process in which heparin likely acts through NF$\mathrm{KB}$ is the decreased degranulation of mast cells and other immune cells after exogenous heparin administration. This decrease subsequently leads to a reduction in lysosomal enzyme activation and reactive oxygen species (ROS) generation. ${ }^{142}$ As heparin was found to be an antioxidant, heparin is possibly exerting its effects through NF-KB given the crosstalk between both ROS and NF-kB. ${ }^{143}$

An important indication of heparin's anti-inflammatory activities in the clinical setting is provided by recently published meta-analyses interrogating the effect of heparin use in 
patients with sepsis. ${ }^{144-146}$ The general outcome of these analyses is that the use of heparin and LMWH results in reduced 28-day mortality in these critically ill patients, despite the recording of an increased number of bleeding events. Septic patients often have a compromised coagulation system. This awareness has prevented a more widespread clinical use of heparin as an anti-inflammatory agent in sepsis. ${ }^{97}$ Since a significant part of heparin's anti-inflammatory actions does not depend on anticoagulant activity, it is hypothesized that heparins with low anticoagulant activity have beneficial therapeutic effects without increasing the risk of bleeding in patients with sepsis. Clinical trials are needed to address this hypothesis.

\section{Adverse Effects of Heparin}

The extensive experience that was gained over the many years of heparin use has revealed several side effects of heparins that may limit their use and should always be considered when heparins are being prescribed. A foremost side effect of anticoagulant heparins is the occurrence of bleeding. For several reasons, depending on the clinical context, a dose of heparin may completely disturb the hemostatic balance such that bleeding occurs. Given the relative short plasma halftime of heparin, this effect is relatively transient as compared with bleeding caused by vitamin $\mathrm{K}$ antagonist use. Moreover in an emergency situation, heparin can be reversed with protamine, a positively charged protein that binds to the negatively charged heparin, upon which the complex is removed from circulation by the reticuloendothelial system. A further well-described and potentially dangerous side effect is the occurrence of heparin-induced thrombocytopenia (HIT), which is estimated to occur in 0.1 to $5 \%$ of patients who receive therapeutic doses of heparin (for a recent review see Sanford et $\mathrm{al}^{147}$ ). HIT can be induced by various types of heparins, but the incidence of HIT is lower with the use of more fractionated heparins, as LMWH. Two types of HIT exist, with the first type, which is less significant in clinical practice, being triggered by the exposure of patients to UFH or high heparin doses for the first time. This a nonimmune thrombocytopenic response caused by binding of heparin to platelet-exposed PF4, resulting in ultralarge complexes (ULCs) that trigger platelet activation or via a fibrinogen receptor mediated lowering of platelet counts. HIT type 2, is an immune-mediated response where antibodies are generated against ULCs. This type of HIT causes life-threatening thromboses and thrombocytopenias and is seen usually 5 to 10 days after the onset of heparin therapy. Immediate cessation of heparin administration is essential to allow increase of platelet counts. A recent guideline by the American Society of Hematology recommends the use of a nonheparin anticoagulant (such as argatroban, bivalirudin, danaparoid, fondaparinux, or DOACs) for treatment of acute HIT. ${ }^{148}$

Data on other adverse effects of heparin use are more scarce. These include the association of heparin use and osteoporosis $^{149}$ and the occurrence of skin lesions. ${ }^{150}$ It is generally accepted that long-term use of UFH is associated with a 2.2 to $5 \%$ incidence of heparin-induced osteoporotic fracture, an effect that is far less clear for LMWH. The molecular mechanism through which heparin induces bone loss is not completely understood, but it likely involves the resorption of bone by osteoclasts, an effect that is stimulated by heparin. At the same time osteoblast function is suppressed, together leading to decreased bone mass. Few data are available on the incidence of heparin-induced skin lesions, but a study from $2009^{150}$ estimated that $7.5 \%$ of patients receiving subcutaneous heparin developed skin lesions, which makes heparininduced skin lesions relatively common. In all these patients a delayed-type hypersensitivity reaction was the cause of the lesion which occurred after prolonged heparin use.

\section{Conclusion and Outlook}

Discovered about a century ago as a water-soluble anticoagulant obtained from animal tissues, heparin has ever since been used in the clinic because of its anticoagulant properties. Clinical use became widespread after Kakkar showed that systematic administration after surgical interventions dramatically decreased postoperative thrombosis with acceptable bleeding risk. Research over the past decades has unveiled diverse nonanticoagulant properties of heparin that potentially have therapeutic value in a variety of diseases with inflammatory components. UFH is a mixture of polysaccharides with variable saccharide compositions and molecular weights. So far it has not been demonstrated that all the polysaccharides in the mixture contribute to the nonanticoagulant properties. Further research is required to delineate the structure-function relationship of the various nonanticoagulant properties, in stark contrast to the structure-function knowledge available in the anticoagulant properties of heparin. Nevertheless, the anticoagulant property of heparin will impact its use in nonanticoagulant applications by limiting the dose due to bleeding risk. One strategy to exploit fully the nonanticoagulant properties therapeutically encompasses the continued formulation of heparins that have no or limited anticoagulant activity.

Conflict of Interest

C.P.R., H.C.H., and G.A.F.N. are inventors of a patent, owned by the Maastricht University, on the use of nonanticoagulant heparin to treat systemic inflammation and sepsis.

\section{References}

1 Shriver Z, Capila I, Venkataraman G, Sasisekharan R. Heparin and heparan sulfate: analyzing structure and microheterogeneity. Handb Exp Pharmacol 2012;(207):159-176

2 Seyrek E, Dubin P. Glycosaminoglycans as polyelectrolytes. Adv Colloid Interface Sci 2010;158(1-2):119-129

3 Smith SA, Morrissey JH. Heparin is procoagulant in the absence of antithrombin. Thromb Haemost 2008;100(01):160-162

4 Oduah EI, Linhardt RJ, Sharfstein ST. Heparin: Past, present, and future. Pharmaceuticals (Basel) 2016;9(03):1-12

5 Bertini S, Bisio A, Torri G, Bensi D, Terbojevich M. Molecular weight determination of heparin and dermatan sulfate by size exclusion chromatography with a triple detector array. Biomacromolecules 2005;6(01):168-173

6 Bertini S, Fareed J, Madaschi L, Risi G, Torri G, Naggi A. Characterization of PF4-heparin complexes by photon correlation spectroscopy and zeta potential. Clin Appl Thromb Hemost 2017;23(07):725-734 
7 Walenga JM, Lyman GH. Evolution of heparin anticoagulants to ultra-low-molecular-weight heparins: a review of pharmacologic and clinical differences and applications in patients with cancer. Crit Rev Oncol Hematol 2013;88(01):1-18

8 Laporte S, Liotier J, Bertoletti L, et al. Individual patient data meta-analysis of enoxaparin vs. unfractionated heparin for venous thromboembolism prevention in medical patients. J Thromb Haemost 2011;9(03):464-472

9 Hirsh J, Warkentin TE, Shaughnessy SG, et al. Heparin and lowmolecular-weight heparin: mechanisms of action, pharmacokinetics, dosing, monitoring, efficacy, and safety. Chest 2001;119 (1, Suppl):64S-94S

10 Bauer KA, Hawkins DW, Peters PC, et al. Fondaparinux, a synthetic pentasaccharide: the first in a new class of antithrombotic agents - the selective factor Xa inhibitors. Cardiovasc Drug Rev 2002;20(01):37-52

11 Sculpher MJ, Lozano-Ortega G, Sambrook J, et al. Fondaparinux versus enoxaparin in non-ST-elevation acute coronary syndromes: short-term cost and long-term cost-effectiveness using data from the Fifth Organization to Assess Strategies in Acute Ischemic Syndromes Investigators (OASIS-5) trial. Am Heart J 2009;157(05):845-852

12 Cassinelli G, Naggi A. Old and new applications of non-anticoagulant heparin. Int J Cardiol 2016;212(Suppl 1):S14-S21

13 Casu B, Oreste P, Torri G, et al. The structure of heparin oligosaccharide fragments with high anti-(factor Xa) activity containing the minimal antithrombin III-binding sequence. Chemical and 13C nuclear-magnetic-resonance studies. Biochem J 1981;197 (03):599-609

14 Thunberg L, Bäckström G, Lindahl U. Further characterization of the antithrombin-binding sequence in heparin. Carbohydr Res 1982;100:393-410

15 Li W, Johnson DJD, Esmon CT, Huntington JA. Structure of the antithrombin-thrombin-heparin ternary complex reveals the antithrombotic mechanism of heparin. Nat Struct Mol Biol 2004;11(09):857-862

16 Olson ST, Björk I, Sheffer R, Craig PA, Shore JD, Choay J. Role of the antithrombin-binding pentasaccharide in heparin acceleration of antithrombin-proteinase reactions. Resolution of the antithrombin conformational change contribution to heparin rate enhancement. J Biol Chem 1992;267(18):12528-12538

17 Quinsey NS, Whisstock JC, Le Bonniec B, Louvain V, Bottomley SP, Pike RN. Molecular determinants of the mechanism underlying acceleration of the interaction between antithrombin and factor Xa by heparin pentasaccharide. J Biol Chem 2002;277(18): 15971-15978

18 Wagenvoord R, Al Dieri R, van Dedem G, Béguin S, Hemker HC. Linear diffusion of thrombin and factor Xa along the heparin molecule explains the effects of extended heparin chain lengths. Thromb Res 2008;122(02):237-245

19 Al Dieri R, Wagenvoord R, van Dedem GWK, Béguin S, Hemker $\mathrm{HC}$. The inhibition of blood coagulation by heparins of different molecular weight is caused by a common functional motif-the Cdomain. J Thromb Haemost 2003;1(05):907-914

20 Cole GJ, Loewy A, Glaser L. Neuronal cell-cell adhesion depends on interactions of N-CAM with heparin-like molecules. Nature 1986;320(6061):445-447

21 Klebe RJ, Escobedo LV, Bentley KL, Thompson LK. Regulation of cell motility, morphology, and growth by sulfated glycosaminoglycans. Cell Motil Cytoskeleton 1986;6(03):273-281

22 Sandset PM, Abildgaard U, Larsen ML. Heparin induces release of extrinsic coagulation pathway inhibitor (EPI). Thromb Res 1988; 50(06):803-813

23 Andrade-Gordon P, Strickland S. Interaction of heparin with plasminogen activators and plasminogen: effects on the activation of plasminogen. Biochemistry 1986;25(14):4033-4040

24 Webb LM, Ehrengruber MU, Clark-Lewis I, Baggiolini M, Rot A. Binding to heparan sulfate or heparin enhances neutrophil responses to interleukin 8. Proc Natl Acad Sci U S A 1993;90 (15):7158-7162

25 Wildhagen KCAA, García de Frutos P, Reutelingsperger CP, et al. Nonanticoagulant heparin prevents histone-mediated cytotoxicity in vitro and improves survival in sepsis. Blood 2014;123 (07):1098-1101

26 Aznar J, España F, Estellés A, Royo M. Heparin stimulation of the inhibition of activated protein $C$ and other enzymes by human protein $\mathrm{C}$ inhibitor-influence of the molecular weightof heparin and ionic strength. Thromb Haemost 1996; 76(06):983-988

27 Chang GMT, Atkinson HM, Berry LR, Chan AKC. Inhibition of plasmin generation in plasma by heparin, low molecular weight heparin, and a covalent antithrombin-heparin complex. Blood Coagul Fibrinolysis 2017;28(06):431-437

28 Nicolaes GAF, Sørensen KW, Friedrich U, et al. Altered inactivation pathway of factor Va by activated protein $C$ in the presence of heparin. Eur J Biochem 2004;271(13):2724-2736

29 Marciniak E, Gockerman JP. Heparin-induced decrease in circulating antithrombin-III. Lancet 1977;2(8038):581-584

30 Liu T, Scallan CD, Broze GJ Jr, Patarroyo-White S, Pierce GF, Johnson KW. Improved coagulation in bleeding disorders by non-anticoagulant sulfated polysaccharides (NASP). Thromb Haemost 2006;95(01):68-76

31 Smith SA, Mutch NJ, Baskar D, Rohloff P, Docampo R, Morrissey $\mathrm{JH}$. Polyphosphate modulates blood coagulation and fibrinolysis. Proc Natl Acad Sci U S A 2006;103(04):903-908

32 Kannemeier C, Shibamiya A, Nakazawa F, et al. Extracellular RNA constitutes a natural procoagulant cofactor in blood coagulation. Proc Natl Acad Sci U S A 2007;104(15):6388-6393

33 Andersson LO, Barrowcliffe TW, Holmer E, Johnson EA, Sims GEC. Anticoagulant properties of heparin fractionated by affinity chromatography on matrix-bound antithrombin iii and by gel filtration. Thromb Res 1976;9(06):575-583

34 Lam LH, Silbert JE, Rosenberg RD. The separation of active and inactive forms of heparin. Biochem Biophys Res Commun 1976; 69(02):570-577

35 Höök M, Björk I, Hopwood J, Lindahl U. Anticoagulant activity of heparin: separation of high-activity and low-activity heparin species by affinity chromatography on immobilized antithrombin. FEBS Lett 1976;66(01):90-93

36 Tkachenko E, Lutgens E, Stan RV, Simons M. Fibroblast growth factor 2 endocytosis in endothelial cells proceed via syndecan-4dependent activation of Rac1 and a Cdc42-dependent macropinocytic pathway. J Cell Sci 2004;117(Pt 15):3189-3199

37 Stewart MD, Sanderson RD. Heparan sulfate in the nucleus and its control of cellular functions. Matrix Biol 2014;35:56-59

38 Friedl A, Filla M, Rapraeger AC. Tissue-specific binding by FGF and FGF receptors to endogenous heparan sulfates. Methods Mol Biol 2001;171:535-546

39 Saksela O, Moscatelli D, Sommer A, Rifkin DB. Endothelial cellderived heparan sulfate binds basic fibroblast growth factor and protects it from proteolytic degradation. J Cell Biol 1988;107 (02):743-751

40 Kato M, Wang H, Kainulainen V, et al. Physiological degradation converts the soluble syndecan-1 ectodomain from an inhibitor to a potent activator of FGF-2. Nat Med 1998;4(06):691-697

41 Ostrovsky O, Berman B, Gallagher J, et al. Differential effects of heparin saccharides on the formation of specific fibroblast growth factor (FGF) and FGF receptor complexes. J Biol Chem 2002;277(04):2444-2453

42 Guerrini M, Agulles T, Bisio A, et al. Minimal heparin/heparan sulfate sequences for binding to fibroblast growth factor- 1 . Biochem Biophys Res Commun 2002;292(01):222-230

43 Soker S, Goldstaub D, Svahn CM, Vlodavsky I, Levi B-Z, Neufeld G. Variations in the size and sulfation of heparin modulate the effect of heparin on the binding of VEGF165 to its receptors. Biochem Biophys Res Commun 1994;203(02):1339-1347 
$44 \mathrm{Li}$ J. Guo ZY, Gao XH, et al. Low molecular weight heparin (LMWH) improves peritoneal function and inhibits peritoneal fibrosis possibly through suppression of HIF- $1 \alpha$, VEGF and TGFB1. PLoS One 2015;10(02):e0118481

45 Kemp MM, Linhardt RJ. Heparin-based nanoparticles. Wiley Interdiscip Rev Nanomed Nanobiotechnol 2010;2(01):77-87

46 Yang Y, Long Y, Wang Y, et al. Enhanced anti-tumor and antimetastasis therapy for triple negative breast cancer by CD44 receptor-targeted hybrid self-delivery micelles. Int J Pharm 2020;577:119085

47 Sanford D, Naidu A, Alizadeh N, Lazo-Langner A. The effect of low molecular weight heparin on survival in cancer patients: an updated systematic review and meta-analysis of randomized trials. J Thromb Haemost 2014;12(07):1076-1085

48 Kuderer NM, Khorana AA, Lyman GH, Francis CW. A metaanalysis and systematic review of the efficacy and safety of anticoagulants as cancer treatment: impact on survival and bleeding complications. Cancer 2007;110(05):1149-1161

49 Borsig L. Antimetastatic activities of heparins and modified heparins. Experimental evidence. Thromb Res 2010;125 (Suppl 2):S66-S71

50 Amirkhosravi A, Meyer T, Amaya M, et al. The role of tissue factor pathway inhibitor in tumor growth and metastasis. Semin Thromb Hemost 2007;33(07):643-652

51 Lindahl AK, Abildgaard U, Stokke G. Release of extrinsic pathway inhibitor after heparin injection: increased response in cancer patients. Thromb Res 1990;59(03):651-656

52 Mousa SA, Linhardt R, Francis JL, Amirkhosravi A. Anti-metastatic effect of a non-anticoagulant low-molecular-weight heparin versus the standard low-molecular-weight heparin, enoxaparin. Thromb Haemost 2006;96(06):816-821

53 Ettelaie C, Fountain D, Collier MEW, Elkeeb AM, Xiao YP, Maraveyas A. Low molecular weight heparin downregulates tissue factor expression and activity by modulating growth factor receptor-mediated induction of nuclear factor-кB. Biochim Biophys Acta Mol Basis Dis 2011;181:1591-1600

54 Alonso D, Bertolesi G, Farias E, Eijan A, Joffe E, Decidre L. Antimetastatic effects associated with anticoagulant properties of heparin and chemically modified heparin species in a mouse mammary tumor model. Oncol Rep 1996;3(01):219-222

55 Koenig A, Norgard-Sumnicht K, Linhardt R, Varki A. Differential interactions of heparin and heparan sulfate glycosaminoglycans with the selectins. Implications for the use of unfractionated and low molecular weight heparins as therapeutic agents. J Clin Invest 1998;101(04):877-889

56 Ludwig RJ, Alban S, Bistrian R, et al. The ability of different forms of heparins to suppress P-selectin function in vitro correlates to their inhibitory capacity on bloodborne metastasis in vivo. Thromb Haemost 2006;95(03):535-540

57 Zhang N, Lou W, Ji F, Qiu L, Tsang BK, Di W. Low molecular weight heparin and cancer survival: clinical trials and experimental mechanisms. J Cancer Res Clin Oncol 2016;142(08):1807-1816

58 Niers TMH, Klerk CPW, DiNisio M, et al. Mechanisms of heparin induced anti-cancer activity in experimental cancer models. Crit Rev Oncol Hematol 2007;61(03):195-207

$59 \mathrm{Ma} \mathrm{L}$, Qiao H, He C, et al. Modulating the interaction of CXCR4 and CXCL12 by low-molecular-weight heparin inhibits hepatic metastasis of colon cancer. Invest New Drugs 2012;30(02):508-517

60 Schlesinger M, Roblek M, Ortmann K, et al. The role of VLA-4 binding for experimental melanoma metastasis and its inhibition by heparin. Thromb Res 2014;133(05):855-862

61 Joseph PRB, Sawant KV, Rajarathnam K. Heparin-bound chemokine CXCL8 monomer and dimer are impaired for CXCR1 and CXCR2 activation: implications for gradients and neutrophil trafficking. Open Biol 2017;7(11):7

62 Gomes AM, Kozlowski EO, Borsig L, Teixeira FCOB, Vlodavsky I, Pavão MSG. Antitumor properties of a new non-anticoagulant heparin analog from the mollusk Nodipecten nodosus: effect on
P-selectin, heparanase, metastasis and cellular recruitment. Glycobiology 2015;25(04):386-393

63 Bar-Ner M, Eldor A, Wasserman L, et al. Inhibition of heparanasemediated degradation of extracellular matrix heparan sulfate by non-anticoagulant heparin species. Blood 1987;70(02):551-557

64 Chen X, Xiao W, Qu X, Zhou S. The effect of dalteparin, a kind of low molecular weight heparin, on lung adenocarcinoma A549 cell line in vitro. Cancer Invest 2008;26(07):718-724

65 Pan Y, Li X, Duan J, et al. Enoxaparin sensitizes human non-smallcell lung carcinomas to gefitinib by inhibiting DOCK1 expression, vimentin phosphorylation, and Akt activation. Mol Pharmacol 2015;87(03):378-390

66 Pfankuchen DB, Baltes F, Batool T, Li J-P, Schlesinger M, Bendas G. Heparin antagonizes cisplatin resistance of A2780 ovarian cancer cells by affecting the Wnt signaling pathway. Oncotarget 2017;8(40):67553-67566

67 Sindrewicz P, Yates EA, Turnbull JE, Lian LY, Yu LG. Interaction with the heparin-derived binding inhibitors destabilizes galectin-3 protein structure. Biochem Biophys Res Commun 2020;523 (02):336-341

68 Yu Y, Lv Q Zhang B, Lan F, Dai Y. Adjuvant therapy with heparin in patients with lung cancer without indication for anticoagulants: A systematic review of the literature with meta-analysis. J Cancer Res Ther 2016;12(Supplement):37-42

69 Groen HJM, van der Heijden EHFM, Klinkenberg TJ, et al; NVALT Study Group, the Netherlands. Randomised phase 3 study of adjuvant chemotherapy with or without nadroparin in patients with completely resected non-small-cell lung cancer: the NVALT-8 study. Br J Cancer 2019;121(05):372-377

70 Macbeth F, Noble S, Evans J, et al. Randomized phase III trial of standard therapy plus low molecular weight heparin in patients with lung cancer: FRAGMATIC trial. J Clin Oncol 2016;34(05): 488-494

71 Meyer G, Besse B, Doubre H, et al. Anti-tumour effect of low molecular weight heparin in localised lung cancer: a phase III clinical trial. Eur Respir J 2018;52(04):1801220

72 Klerk CPW, Smorenburg SM, Otten H-M, et al. The effect of low molecular weight heparin on survival in patients with advanced malignancy. J Clin Oncol 2005;23(10):2130-2135

73 Lee AYY, Rickles FR, Julian JA, et al. Randomized comparison of low molecular weight heparin and coumarin derivatives on the survival of patients with cancer and venous thromboembolism. J Clin Oncol 2005;23(10):2123-2129

74 Kakkar AK, Levine MN, Kadziola Z, et al. Low molecular weight heparin, therapy with dalteparin, and survival in advanced cancer: the fragmin advanced malignancy outcome study (FAMOUS). J Clin Oncol 2004;22(10):1944-1948

75 Kragh M, Binderup L, Vig Hjarnaa PJ, Bramm E, Johansen KB, Frimundt Petersen C. Non-anti-coagulant heparin inhibits metastasis but not primary tumor growth. Oncol Rep 2005;14(01): 99-104

76 Stevenson JL, Varki A, Borsig L. Heparin attenuates metastasis mainly due to inhibition of P- and L-selectin, but non-anticoagulant heparins can have additional effects. Thromb Res 2007;120 (Suppl 2):S107-S111

77 Liao WY, Ho CC, Hou HH, et al. Heparin co-factor II enhances cell motility and promotes metastasis in non-small cell lung cancer.J Pathol 2015;235(01):50-64

78 Alyahya R, Sudha T, Racz M, Stain SC, Mousa SA. Anti-metastasis efficacy and safety of non-anticoagulant heparin derivative versus low molecular weight heparin in surgical pancreatic cancer models. Int J Oncol 2015;46(03):1225-1231

79 Chen Z, Jing Y, Song B, Han Y, Chu Y. Chemically modified heparin inhibits in vitro L-selectin-mediated human ovarian carcinoma cell adhesion. Int J Gynecol Cancer 2009;19(04):540-546

80 Oschatz C, Maas C, Lecher B, et al. Mast cells increase vascular permeability by heparin-initiated bradykinin formation in vivo. Immunity 2011;34(02):258-268 
81 Adam A, Montpas N, Keire D, et al. Bradykinin forming capacity of oversulfated chondroitin sulfate contaminated heparin in vitro. Biomaterials 2010;31(22):5741-5748

82 Stelmach I, Jerzynska J, Stelmach W, et al. The effect of inhaled heparin on airway responsiveness to histamine and leukotriene D4. Allergy Asthma Proc 2003;24(01):59-65

83 Vancheri C, Mastruzzo C, Armato F, et al. Intranasal heparin reduces eosinophil recruitment after nasal allergen challenge in patients with allergic rhinitis. J Allergy Clin Immunol 2001;108 (05):703-708

84 Özkurt YB, Taşkiran A, Erdogan N, Kandemir B, Doğan ÖK. Effect of heparin in the intraocular irrigating solution on postoperative inflammation in the pediatric cataract surgery. Clin Ophthalmol 2009;3:363-365

85 Ledson M, Gallagher M, Hart CA, Walshaw M. Nebulized heparin in Burkholderia cepacia colonized adult cystic fibrosis patients. Eur Respir J 2001;17(01):36-38

86 Lakshmi RTS, Priyanka T, Meenakshi J, Mathangi KR, Jeyaraman $\mathrm{V}$, Babu M. Low molecular weight heparin mediated regulation of nitric oxide synthase during burn wound healing. Ann Burns Fire Disasters 2011;24(01):24-29

87 Becker RC, Mahaffey KW, Yang H, et al; SYNERGY Investigators. Heparin-associated anti-Xa activity and platelet-derived prothrombotic and proinflammatory biomarkers in moderate to high-risk patients with acute coronary syndrome. J Thromb Thrombolysis 2011;31(02):146-153

88 Aldea GS, Doursounian M, O'Gara P, et al. Heparin-bonded circuits with a reduced anticoagulation protocol in primary CABG: a prospective, randomized study. Ann Thorac Surg 1996;62(02):410-417

89 Rathbun SW, Aston CE, Whitsett TL. A randomized trial of dalteparin compared with ibuprofen for the treatment of superficial thrombophlebitis. J Thromb Haemost 2012;10(05): 833-839

90 Scheffert JL, Taber DJ, Pilch NA, Chavin KD, Baliga PK, Bratton CF. Clinical outcomes associated with the early postoperative use of heparin in pancreas transplantation. Transplantation 2014;97 (06):681-685

91 Sedigh A, Nordling S, Carlsson F, et al. Perfusion of porcine kidneys with macromolecular heparin reduces early ischemia reperfusion injury. Transplantation 2019;103(02):420-427

92 Lever R, Page CP. Novel drug development opportunities for heparin. Nat Rev Drug Discov 2002;1(02):140-148

93 Weiler JM, Edens RE, Linhardt RJ, Kapelanski DP. Heparin and modified heparin inhibit complement activation in vivo. J Immunol 1992;148(10):3210-3215

94 Linhardt RJ, Rice KG, Kim YS, Engelken JD, Weiler JM. Homogeneous, structurally defined heparin-oligosaccharides with low anticoagulant activity inhibit the generation of the amplification pathway C3 convertase in vitro. J Biol Chem 1988;263(26): 13090-13096

95 Proudfoot AEI, Fritchley S, Borlat F, et al. The BBXB motif of RANTES is the principal site for heparin binding and controls receptor selectivity. J Biol Chem 2001;276(14):10620-10626

96 Kuschert GSV, Coulin F, Power CA, et al. Glycosaminoglycans interact selectively with chemokines and modulate receptor binding and cellular responses. Biochemistry 1999;38(39): 12959-12968

97 Young E, Podor TJ, Venner T, Hirsh J. Induction of the acute-phase reaction increases heparin-binding proteins in plasma. Arterioscler Thromb Vasc Biol 1997;17(08):1568-1574

98 Brinkmann V, Reichard U, Goosmann C, et al. Neutrophil extracellular traps kill bacteria. Science 2004;303(5663):1532-1535

99 Saffarzadeh M, Juenemann C, Queisser MA, et al. Neutrophil extracellular traps directly induce epithelial and endothelial cell death: a predominant role of histones. PLoS One 2012;7(02):e32366

100 Iba T, Hashiguchi N, Nagaoka I, Tabe Y, Kadota K, Sato K. Heparins attenuated histone-mediated cytotoxicity in vitro and improved the survival in a rat model of histone-induced organ dysfunction. Intensive Care Med Exp 2015;3(01):36

101 Longstaff C, Hogwood J, Gray E, et al. Neutralisation of the anticoagulant effects of heparin by histones in blood plasma and purified systems. Thromb Haemost 2016;115(03):591-599

102 Freeman CG, Parish CR, Knox KJ, et al. The accumulation of circulating histones on heparan sulphate in the capillary glycocalyx of the lungs. Biomaterials 2013;34(22):5670-5676

103 Redini F, Tixier JM, Petitou M, Choay J, Robert L, Hornebeck W. Inhibition of leucocyte elastase by heparin and its derivatives. Biochem J 1988;252(02):515-519

104 von Brühl ML, Stark K, Steinhart A, et al. Monocytes, neutrophils, and platelets cooperate to initiate and propagate venous thrombosis in mice in vivo. J Exp Med 2012;209(04):819-835

105 Coughlin SR. Thrombin signalling and protease-activated receptors. Nature 2000;407(6801):258-264

106 Levi M, van der Poll T. Inflammation and coagulation. Crit Care Med 2010;38(2, Suppl):S26-S34

107 Borissoff JI, Spronk HM, ten Cate H. The hemostatic system as a modulator of atherosclerosis. N Engl J Med 2011;364(18): $1746-1760$

108 Connor WE, Armstrong ML. Plasma lipoprotein lipase after subcutaneous heparin. Circulation 1961;24:87-93

109 Lever R, Hoult JRS, Page CP. The effects of heparin and related molecules upon the adhesion of human polymorphonuclear leucocytes to vascular endothelium in vitro. $\mathrm{Br} \mathrm{J}$ Pharmacol 2000; 129(03):533-540

110 Wan MX, Zhang XW, Törkvist L, Thorlacius H. Low molecular weight heparin inhibits tumor necrosis factor $\alpha$-induced leukocyte rolling. Inflamm Res 2001;50(12):581-584

111 Skinner MP, Lucas CM, Burns GF, Chesterman CN, Berndt MC. GMP-140 binding to neutrophils is inhibited by sulfated glycans. J Biol Chem 1991;266(09):5371-5374

112 Nelson RM, Cecconi O, Roberts WG, Aruffo A, Linhardt RJ, Bevilacqua MP. Heparin oligosaccharides bind L- and P-selectin and inhibit acute inflammation. Blood 1993;82(11):3253-3258

113 Xie X, Thorlacius H, Raud J, Hedqvist P, Lindbom L. Inhibitory effect of locally administered heparin on leukocyte rolling and chemoattractant-induced firm adhesion in rat mesenteric venules in vivo. Br J Pharmacol 1997;122(05):906-910

114 Wang L, Fuster M, Sriramarao P, Esko JD. Endothelial heparan sulfate deficiency impairs L-selectin- and chemokine-mediated neutrophil trafficking during inflammatory responses. Nat Immunol 2005;6(09):902-910

115 Revelle BM, Scott D, Beck PJ. Single amino acid residues in the Eand P-selectin epidermal growth factor domains can determine carbohydrate binding specificity. J Biol Chem 1996;271(27): 16160-16170

116 Manduteanu I, Voinea M, Antohe F, et al. Effect of enoxaparin on high glucose-induced activation of endothelial cells. Eur J Pharmacol 2003;477(03):269-276

117 Kitamura N, Yamaguchi M, Shimabukuro K, Miyasaka M, Nakano H, Kumada K. Heparin-like glycosaminoglycans inhibit leukocyte adhesion to endotoxin-activated human vascular endothelial cells under nonstatic conditions. Eur Surg Res 1996;28(06): 428-435

118 Miller SJ, Hoggat AM, Faulk WP. Heparin regulates ICAM-1 expression in human endothelial cells: an example of noncytokine-mediated endothelial activation. Thromb Haemost 1998;80(03):481-487

119 Coombe DR, Stevenson SM, Kinnear BF, et al. Platelet endothelial cell adhesion molecule 1 (PECAM-1) and its interactions with glycosaminoglycans: 2. Biochemical analyses. Biochemistry 2008;47(17):4863-4875

120 dela Paz NG, Melchior B, Shayo FY, Frangos JA. Heparan sulfates mediate the interaction between platelet endothelial cell adhesion molecule-1 (PECAM-1) and the G $\alpha \mathrm{q} / 11$ subunits of heterotrimeric G proteins. J Biol Chem 2014;289(11):7413-7424 
121 Kiselyov VV, Berezin V, Maar TE, et al. The first immunoglobulinlike neural cell adhesion molecule (NCAM) domain is involved in double-reciprocal interaction with the second immunoglobulinlike NCAM domain and in heparin binding. J Biol Chem 1997;272 (15):10125-10134

122 Diamond MS, Alon R, Parkos CA, Quinn MT, Springer TA. Heparin is an adhesive ligand for the leukocyte integrin Mac-1 (CD11b/CD1). J Cell Biol 1995;130(06):1473-1482

123 Baba M, Pauwels R, Balzarini J, Arnout J, Desmyter J, De Clercq E. Mechanism of inhibitory effect of dextran sulfate and heparin on replication of human immunodeficiency virus in vitro. Proc Natl Acad Sci U S A 1988;85(16):6132-6136

124 Lederman S, Gulick R, Chess L. Dextran sulfate and heparin interact with CD4 molecules to inhibit the binding of coat protein (gp120) of HIV. J Immunol 1989;143(04):1149-1154

$125 \mathrm{Hu}$ Q-YFE, Fink E, Grant CK, Elder JH. Selective interaction of heparin with the variable region 3 within surface glycoprotein of laboratory-adapted feline immunodeficiency virus. PLoS One 2014;9(12):e115252

126 Gonzales JN, Kim KM, Zemskova MA, et al. Low anticoagulant heparin blocks thrombin-induced endothelial permeability in a PAR-dependent manner. Vascul Pharmacol 2014;62(02):63-71

127 Achilles A, Mohring A, Dannenberg L, et al. Dabigatran enhances platelet reactivity and platelet thrombin receptor expression in patients with atrial fibrillation. J Thromb Haemost 2017;15(03): 473-476

128 Blaukovitch CIPR, Pugh R, Gilotti AC, Kanyi D, Lowe-Krentz LJ. Heparin treatment of vascular smooth muscle cells results in the synthesis of the dual-specificity phosphatase MKP-1. J Cell Biochem 2010;110(02):382-391

129 Stewart EM, Liu X, Clark GM, Kapsa RMI, Wallace GG. Inhibition of smooth muscle cell adhesion and proliferation on heparindoped polypyrrole. Acta Biomater 2012;8(01):194-200

130 Kanabar V, Hirst SJ, O'Connor BJ, Page CP. Some structural determinants of the antiproliferative effect of heparin-like molecules on human airway smooth muscle. Br J Pharmacol 2005; 146(03):370-377

131 Guyton JR, Rosenberg RD, Clowes AW, Karnovsky MJ. Inhibition of rat arterial smooth muscle cell proliferation by heparin. In vivo studies with anticoagulant and nonanticoagulant heparin. Circ Res 1980;46(05):625-634

132 Li X, Li Z, Zheng Z, Liu Y, Ma X. Unfractionated heparin ameliorates lipopolysaccharide-induced lung inflammation by downregulating nuclear factor-kB signaling pathway. Inflammation 2013;36(06):1201-1208

133 Luan ZG, Naranpurev M, Ma XC. Treatment of low molecular weight heparin inhibits systemic inflammation and prevents endotoxin-induced acute lung injury in rats. Inflammation 2014; 37(03):924-932

134 Yini S, Heng Z, Xin A, Xiaochun M. Effect of unfractionated heparin on endothelial glycocalyx in a septic shock model. Acta Anaesthesiol Scand 2015;59(02):160-169

135 Lipowsky $\mathrm{HH}$, Lescanic A. Inhibition of inflammation induced shedding of the endothelial glycocalyx with low molecular weight heparin. Microvasc Res 2017;112:72-78
136 Nelson A, Berkestedt I, Schmidtchen A, Ljunggren L, Bodelsson M. Increased levels of glycosaminoglycans during septic shock: relation to mortality and the antibacterial actions of plasma. Shock 2008;30(06):623-627

137 Floer M, Götte M, Wild MK, et al. Enoxaparin improves the course of dextran sodium sulfate-induced colitis in syndecan-1-deficient mice. Am J Pathol 2010;176(01):146-157

138 Li X, Zheng Z, Li X, Ma X. Unfractionated heparin inhibits lipopolysaccharide-induced inflammatory response through blocking p38 MAPK and NF-KB activation on endothelial cell. Cytokine 2012;60(01):114-121

139 Luan Z, Hu B, Wu L, et al. Unfractionated heparin alleviates human lung endothelial barrier dysfunction induced by high mobility group box 1 through regulation of P38-GSK3 $\beta$-snail signaling pathway. Cell Physiol Biochem 2018;46(05):1907-1918

140 Lee JH, Lee J, Seo GH, Kim CH, Ahn YS. Heparin inhibits NFkappaB activation and increases cell death in cerebral endothelial cells after oxygen-glucose deprivation. J Mol Neurosci 2007; 32(02):145-154

141 Hochart H, Jenkins PV, Smith OP, White B. Low-molecular weight and unfractionated heparins induce a downregulation of inflammation: decreased levels of proinflammatory cytokines and nuclear factor-kappaB in LPS-stimulated human monocytes. $\mathrm{Br}$ J Haematol 2006;133(01):62-67

142 Dandona P, Qutob T, Hamouda W, Bakri F, Aljada A, Kumbkarni Y. Heparin inhibits reactive oxygen species generation by polymorphonuclear and mononuclear leucocytes. Thromb Res 1999; 96(06):437-443

143 Morgan MJ, Liu ZG. Crosstalk of reactive oxygen species and NFKB signaling. Cell Res 2011;21(01):103-115

144 Fan Y, Jiang M, Gong D, Zou C. Efficacy and safety of lowmolecular-weight heparin in patients with sepsis: a meta-analysis of randomized controlled trials. Sci Rep 2016;6:25984

145 Wang C, Chi C, Guo L, et al. Heparin therapy reduces 28-day mortality in adult severe sepsis patients: a systematic review and meta-analysis. Crit Care 2014;18(05):563

146 Zarychanski R, Abou-Setta AM, Kanji S, et al; Canadian Critical Care Trials Group. The efficacy and safety of heparin in patients with sepsis: a systematic review and metaanalysis. Crit Care Med 2015;43(03):511-518

147 Zhou P, Yin JX, Tao HL, Zhang HW. Pathogenesis and management of heparin-induced thrombocytopenia and thrombosis. Clin Chim Acta 2020;504:73-80

148 Cuker A, Arepally GM, Chong BH, et al. American Society of Hematology 2018 guidelines for management of venous thromboembolism: heparin-induced thrombocytopenia. Blood Adv 2018;2(22):3360-3392

149 Lefkou E, Khamashta M, Hampson G, Hunt BJ. Review: Lowmolecular-weight heparin-induced osteoporosis and osteoporotic fractures: a myth or an existing entity? Lupus 2010;19(01): 3-12

150 Schindewolf M, Paulik M, Kroll H, et al. Low incidence of heparininduced skin lesions in orthopedic surgery patients with lowmolecular-weight heparins. Clin Exp Allergy 2018;48(08): 1016-1024 